\section{И.И. Евсюкова}

Научно-исследовательский институт акушерства и гинекологии им. Д.О. Отта РАМН, Санкт-Петербург

\section{ПАТОГЕНЕЗ ПЕРИНАТАЛЬНОЙ ПАТОЛОГИИ У НОВОРОЖДЕННЫХ ДЕТЕЙ, РАЗВИВАВШИХСЯ В УСЛОВИЯХ ХРОНИЧЕСКОЙ ГИПОКСИИ ПРИ ПЛАЦЕНТАРНОЙ НЕДОСТАТОЧНОСТИ}

Изучение патогенетических аспектов нарушений формирования функций ЦНС и других жизненно важных функциональных систем организма ребенка при неблагоприятных условиях его внутриутробного развития всегда являлось приоритетным направлением научных исследований сотрудников отделения физиологии и патологии новорожденных детей НИИ АГ им. Д.О. Отта РАМН. В последнее время эта проблема приобрела особую актуальность в связи с увеличением числа беременных, имеюших плацентарную недостаточность и синдром задержки внутриутробного развития плода (3ВУР) [4, 12], что определяет не только высокую перинатальную заболеваемость и смертность, но и значительные отклонения нервно-психического и соматического развития детей в последующие годы жизни $[2,11,15,17]$. Чем раньше плод начинает испытывать патогенные воздействия, тем больше степень отставания морфологического, биохимического и функционального развития мозга и более выражены у новорожденных нарушения функций ЦНС, сердечно-сосудистой системы, дыхания, расстройства гомеостаза, что значительно затрудняет их постнатальную адаптацию и увеличивает вероятность неблагоприятных последствий.

Фундаментальные экспериментальные, клинические и морфологические исследования Г.П. Поляковой, проведенные еще в 50 -е годы XX в. и получившие в последнее десятилетие подтверждение в работах отечественных и зарубежных авторов при использовании новых технологий, показали, что в основе поражений ЦНС, выявляемых у новорожденных детей, лежит нарушение кровообрашения плода, возникающее в результате хронического или острого расстройства маточно-плацентарного кровообращения и связанной с ним асфиксии [10]. Углубление гипоксии ведет к изменению функционального состояния дыхательного и сосудодвигательного центров, падению тонуса сосудов мозга, повышению их проницаемости, появлению периваскулярного отека, что, в свою очередь, углубляет гипоксию и способствует возникновению тяжелых изменений состояния нервных клеток вплоть до некроза. Впервые Г.П. Поляковой был введен в неонатологию диагноз «нарушение мозгового кровообращения» (НMK) и был сделан важный вывод: клинические проявления НМК у новорожденных детей связаны не столько с локальными поражениями мозга, сколько с общими изменениями состояния его структурных элементов, возникающими на почве длительной гипоксии. Закономерная смена клинических стадий болезни отражает последовательность восстановления функций различных отделов мозга после перенесенной гипоксии.

Результаты дальнейших исследований сотрудников существенно углубили представление о генезе нарушений интегративной деятельности ЦНС, наиболее выраженных при длительной внутриутробной гипоксии плода. Показано, что характеристика именно этой функции ЦНС позволяет оценить тяжесть поражения мозга ребенка и способность к восстановлению нарушенных функций [5]. 
Основанием для данного утверждения послужили результаты изучения особенностей формирования циклической организации сна и механизмов регуляции деятельности функциональных систем (дыхания, сердечно-сосудистой, терморегуляции и др.) при неблагоприятных условиях внутриутробного развития и связанной с этим перинатальной патологии (нарушение мозгового кровообрашения, задержка внутриутробного развития, внутриугробные инфекции). Установлено, что у детей, перенесших хроническую гипоксию, нарушено формирование циклической организации сна, что выражается отсутствием электроэнцефалографических признаков дифференциации ортодоксальной и парадоксальной фаз сна и наличием качественных изменений состояния вегетативных и двигательных реакций. Был выделен малоактивированный тип недифференцированного сна, при котором наблюдается низкая окуломоторная и двигательная активность в сочетании с монотонным сердечным ритмом. Известно, что активация мозговых структур в период парадоксального сна ребенка способствует формированию межцентральных связей и поэтому крайне необходима для развития ребенка, тем более что есть основания рассматривать эту фазу сна как канал реализации генетически запрограммированных личностных особенностей человека. Преобладание у перенесшего гипоксию ребенка малоактивированного сна свидетельствует о глубоких нарушениях функционального состояния мозговых структур и дезинтеграции их деятельности. Результаты исследований Т.Г. Шевченко [14] показали, что в этих случаях нарушена регуляция мозгового кровообрашения, направленная на нормализацию циркуляторного гомеостаза мозга (ауторегуляция мозгового кровообрашения): в период усиления его функциональной активности снижена скорость мозгового кровотока и кровенаполнение мозга, т. е. регистрируется монотонный мозговой кровоток. Неадекватное кровоснабжение головного мозга, сохраняющееся в раннем постнатальном онтогенезе у детей, перенесших гипоксию, способствует поддержанию изменений гомеостаза на клеточном уровне. Об этом свидетельствует наличие у таких детей значительного снижения проницаемости эритроцитарных мембран и сорбционной способности эритроцитов, что определяет генез неврологических расстройств в период ранней постнатальной адаптации [3].

Сопоставление результатов оценки неврологического статуса ребенка с данными нейрофизиологических исследований показало, что становление в онтогенезе познотонических и безусловных рефлексов тесно связано с процес- сом формирования циклической организации сна. Оказалось, что у детей, развивавшихся в условиях хронической гипоксии, наблюдается задержка формирования познотонических и безусловных рефлексов, но в одних случаях выявляется равномерная, а в других - диссоциированная задержка развития, когда формирование рудиментарных безусловных рефлексов новорожденных отстает в большей степени (на 2-4 недели) по сравнению с развитием познотонических рефлексов. Сопоставление полученных данных с психомоторным развитием детей показало, что оно значительно задерживается на первом году жизни ребенка только при сочетании диссоциации формирования рефлексов и малоактивированного недифференцированного сна. В остальных случаях имеется темповая задержка развития, которая нивелируется к 6-7 месяцам жизни [13].

Кроме того, было установлено, что при сочетании задержки формирования функший ЦНС с отставанием от должных к данному гестационному возрасту ребенка величин массы тела и роста наблюдается не только высокая частота нарушений функций ЦНС, но сердечно-сосудистой и дыхательной систем. Так, среди детей с симметричной формой ЗВУР каждый второй имеет полиорганную недостаточность. Наряду с нарушением функционального состояния ЦНС, которое у большинства этих детей клинически проявляется в виде длительно сохраняюшегося синдрома угнетения ЦНС, наблюдается нестабильность артериального давления, глухость сердечных тонов, систолический шум вследствие позднего закрытия фетальных коммуникаций. По данным электрокардиографии отмечаются признаки перегрузки правых и левых отделов сердца, метаболические нарушения в миокарде. ЭхоКГ исследования выявляют снижение сократительной способности миокарда, повышение удельного периферического сосудистого сопротивления, снижение показателей производительности сердца: конечно-систолического, конечнодиастолического и ударного объемов, минутного объема крови. Установлена высокая частота дыхательных расстройств, в генезе которых ведушую роль играет нарушение гемодинамики в легких и, как следствие, вентиляционно-перфузионных отношений, о чем свидетельствует наличие у большинства высокого градиента ( $>20$ мм рт. ст.) между содержанием $\mathrm{CO}_{2}$ в конечной порции выдыхаемого воздуха и артериализованной капиллярной крови. Наряду с этим страдает гомеостатическая и выделительная функции почек. Таким образом, полученные данные свидетельствуют, что в генезе полиорганной недостаточности существенную 
роль играет расстройство регуляции на тканевом и клеточном уровнях.

Учитывая важную роль мелатонина в координации межклеточных взаимоотношений и интеграции деятельности всех функциональных систем организма, в регуляции экспрессии генов и антиоксидантной защиты [8, 18], была изучена его продукция у детей с ЗВУР при хронической плацентарной недостаточности. Оказалось, что она не только значительно снижена, но и отсутствует характерный для здоровых новорожденных детей суточный ритм. Так, содержание в моче у детей с 3ВУР 6-сульфатоксимелатонина, основного метаболита мелатонина, составляет в дневное время $3,94 \pm 1,34 \mathrm{Hr} /$ мл, в ночное $3,45 \pm 1,34$ нг/мл, тогда как в норме соответственно 14,6 $\pm 2,5$ нг/мл и $6,6 \pm 1,5$ нг/мл, причем на протяжении первых двух недель жизни низкая продукция мелатонина сохраняется [6].

Нами установлена обратная корреляционная связь между продукцией мелатонина и активностью мозговой фракщии креатинкиназы $(\mathrm{r}=-0,71$, $\mathrm{p}=0,003)$, которая повышается при тяжелом повреждении клеток мозга вследствие хронической гипоксии. Так, у детей с тяжелой формой ЗВУР и отставанием формирования функций ЦНС имеются высокие значения активности креатинкиназы и ее изоферментов. Особенно выраженное изменение активности СК-ВВ наблюдалось у новорожденных с симметричной фор-

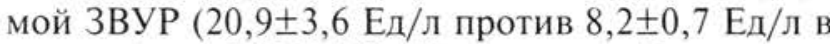
норме $(p=0,005)$ [6]. Кроме того, было установлено, что у доношенных и недоношенных новорожденных детей, перенесших гипоксию, резко возрастает экскреция нитратов и нитритов, что указывает на повышение продукции оксида азота, степень которого зависит от продолжительности и тяжести гипоксии. Сохранение высокой экскреции нитратов и нитритов вплоть до 4 дня жизни также коррелирует с большей тяжестью неврологических расстройств [1].

Как известно, мелатонин инактивирует свободные радикалы и пероксинитрит, образующийся в результате метаболизма окиси азота, нормализует тромбоцитарно-сосудистый гомеостаз и оказывает иммуномодулирующее действие [6, 18]. Учитывая тот факт, что рецепторы к мелатонину появляются во всех органах и тканях уже на самых ранних стадиях внутриутробного развития плода, а количество мелатонина в организме плода существенно возрастает по мере прогрессирования беременности $[19,20]$, есть основание полагать, что возникающее в условиях длительной хронической гипоксии нарушение продукции мелатонина и, возможно, других нейромедиаторов, нейромодуляторов, нейрогормонов и цито- кинов лежит в основе ЗВУР ребенка и полиорганной функщиональной недостаточности, наблюдаемой при адаптации его к новым условиям окружающей среды.

В связи с этим встает вопрос о необходимости проведения уже в раннем неонатальном периоде жизни ребенка патогенетической терапии, направленной на быстрое восстановление и компенсацию нарушенных функций в целях профилактики неблагоприятных последствий. Учитывая высокую эффективность цитомединов (низкомолекулярных пептидных биорегуляторов) при лечении у детей и у взрослых нарушений мозгового кровообращения, последствий нейроинфекций, астенических состояний и другой неврологической патологии [9] было проведено прямое рандомизированное исследование клинической эффективности эпиталамина в качестве антиоксиданта, иммуномодулятора и средства, оказывающего стимулируюшее влияние на продукцию мелатонина у новорожденных детей, перенесших хроническую гипоксию и имеюших задержку внутриутробного развития. Первую группу (основную) составили 20 новорожденных, которым со второго дня жизни ежедневно в течение 10 дней внутримышечно вводили эпиталамин в дозе 1 мг/кг массы тела. В период лечения эпиталамином других препаратов они не получали. Вторую (контрольную) группу составили 15 новорожденных детей, которым с первых дней жизни проводили общепринятую терапию: витамин Е $10 \%$ в/м по 0,1 мл/кг ежедневно в течение 5 дней и затем через 2 раза через 2 дня, глютаминовую кислоту, внутривенные инфузии трентала с глюкозой в течение 2-3-х дней жизни, поливитамины в возрастной дозировке, а также симптоматическую терапию. Все дети вскармливались материнским молоком из рожка, затем прикладывались к груди матери в зависимости от их клинического состояния.

В результате лечения эпиталамином у детей основной группы наблюдалась быстрая нормализации сна, появлялся сосательный рефлекс, исчезал тремор конечностей. Наряду с этим происходило ускоренное формирование познотонических и рефлекторных реакций. К концу второй недели жизни лишь у $40 \%$ детей (в том числе и у имевших ранее диссоциированную форму задержки развития функций) отмечалась отставание развития функций ЦНС только на 2 недели от положенного для данного гестационного возраста. В то же время у детей контрольной группы до 3 дня жизни наблюдалось нарастание неврологических симптомов, которые медленно регрессировали лишь к концу второй недели жизни. За этот период жизни у них не произошло существенного развития функций ЦНС. Следо- 
вательно, применение пептидного биорегулятора эпиталамина в качестве монотерапии в раннем неонатальном периоде жизни у детей с задержкой внутриутробного развития и отставанием функционального развития ЦНС является эффективным для лечения неблагоприятных последствий ЗВУР.

Таким образом, результаты комплексных исследований, проведенных сотрудниками отделения физиологии и патологии новорожденных детей, открывают новое направление в изучении патогенеза нарушений развития функциональных систем организма плода в условиях хронической плацентарной недостаточно́сти и указывают на перспективы использования пептидных биорегуляторов для профилактики и своевременной коррекции уже имеюшихся нарушений у новорожденных детей.

\section{Литература}

1. Андреева A.A. Продукция окиси азота (NO) и состояние центральной гемодинамики у новорожденных детей, здоровыхи перенесшизх гипоксию: Автореф. дисс. . канд. мед. наук. - СПб., 1999. - 19 с.

2. Барашнев Ю.И. Гипоксическая энцефалопатия: гипотезы патогенеза церебральных расстройств и поиск методов лекарственной терапии // Рос. Вест. перинатол. и педиатрии. - 2002. - Т. 47, № 1. - С. 6-13.

3. Додхоев Д.С. Проницаемость эритроцитарных мембран и сорбционная способность эритроцитов у родильниц и их новорожденных детей с перинатальной патологией // Автореф. дисс ... канд. мед. наук. - СПб., 1999 - 19 С.

4. Евсеенко Д.А., Ещенко Ю.В. Изменения в фетоплацентарном комплексе при острой и хронической внутриутробной гипоксии // Педиатрия. - 2002. - № 1. C. 5-9.

5. Евсюкова И.И. Формирование функций ЦНС и патогенез нарушений при неблагоприятных условиях внутриутробного развития ребенка (диагностика, прогноз, лечение) // Вестник Росс, ассоциации акуш. гинекол. - 1997. - № 3. C. $31-36$.

6. Евсюкова И.И., Додхоев Д.С., Ковальчук-Ковалевская $O . B$. Недоношенные дети со Звур (проблемы развития, лечение)// Материалы научно-практической конференции: «Невынашивание беременности и недоношенный ребенок". - Петрозаводск, 17-19 июня, 2002. - C. $45-46$.
7. Евсюкова И.И. Недоношенный ребенок (морфофункциональная зрелость и принципы выхаживания) // Материалы научно-практической конференции: "Невынашивание беременности и недоношенный ребенок». - Петрозаводск, 17-19 июня, 2002 - C. $43-45$

8. Малиновская Н.К. Роль мелатонина в организме человека // Клин. мед. - 1998. - Т. 76, № 10. - С. 15-23

9. Морозов В.Г., Хавинсон В.Х. Пептидные биорегуляторы (25-летний опыт экспериментального и клинического изучения) - СПб.: Наука, $1996-74$ с.

10. Полякова Г.П. Патогенез и клиника так называемой внутричерепной травмы новорожденных детей: Автореф. дисс. ... канд. мед. наук. - Л., 1955, - 24 С

11. Самсыгина Г.А., Дементьева Г.М., Талалаев А.Г. Здоровье плода и новорожденного: современное состояние и прогноз // Педиатрия. - 1999. - № 5. - С. 4-6.

12. Стрижаков А.Н., Мусаев 3.М., Тимохина Т.Ф. и др. Системные нарушения гемодинамики при синдроме задержки роста плода как фактор риска гипоксическиишемических поражений ЦНС и отклонений психомоторного развития детей // Акуш. гинекол. 2003. - № 1. - C. 11-16

13. Фоменко Б.А. Влияние условий внутриутробного развития на формирование перинатальной патологии ЦНС у недоношенных детей: Автореф. дисс.... канд. мед наук. $-\pi .-24 \mathrm{C}$

14. Шевченко О.T. Состояние мозгового кровообращения в цикле сна у здоровыхи перенесших гипоксию новорожденных детей: Автореф. дисс... канд. мед. наук Л., $1986,-24 \mathrm{C}$

15. Ширяева Т.Ю., Логачев М.Ф., Розанова Г.Н. Современные представления о задержке внутриутробного развития // Лекции по актуальным проблемам педиатрии / Под ред. В.Ф.Демина и С.О. Ключникова. - М.: РГМУ - 2000 - C. 167-174

16. Cuzzocrea S., Costantino G., Caputi A.P. Protective effect of melatonin oncellular energy depletion medisted by peroxynitrite and poly (ADP-ribose) synthetase activation in a non-septic chock model induced by zymosan in the rat // J. Pineal Res - 1998. - Vol. 25, N 2 - P. 78-85.

17. Gordon N. Some influences on cognition in early life: a short review of recent opinions // Eur J. Paediatr. Neurol. 1998. Vol. 2, N 1. - P. 1-5

18. Lipartiti M., Franceschini D., Lanoni R. et al. Neuroprotective effects of melatonin // Adv. Exper. Med. Biol. - 1996. - Vol. 398 - P. 315-321.

19. Thomas L., Drew J.E., Abramovich D.R., Williams L.M. The role of melatonin in the human fetus // Int. J. Mol. Med. - 1998. - Vol. 1, N 3. - P. 539-43.

20. Yuan H., Lu Y., Pang S.F. Binding characteristics and regional distribution of (125) iodomelatonin binding sites in the brain of the human fetus // Neurosci Lett. - Vol. 130 , N 2. - P. 229-32. 